\title{
Multidisciplinary Psychosomatic Assessment for UX Design Evaluation
}

\author{
ANDREA BONACCHI, Centro Studi e Ricerca Synthesis, Firenze, Italy \\ ANTONELLA FERRARI, Centro Studi e Ricerca Synthesis, Firenze, Italy \\ LELIO CAMILLERI, Centro Tempo Reale, Firenze, Italy \\ FRANCESCA CHIESI, University of Florence, Italy
}

\begin{abstract}
"In the mirror of the Wonder of Luca Giordano" was a multi-sensorial experience created in the gallery frescoed by Luca Giordano in Palazzo Medici Riccardi, in Florence; the project involved different disciplines and researchers. The entire experience was subjected to an impact analysis, combining principally psychophysiological, qualitative psychological and neuro-physiological aspects. In most of the visitors who participated in the study the experience evoked a sense of pleasure, enjoyment, relaxation, lightness, spacetime suspension, involvement and immersion. In many of the visitors, the devices detected changes in heartbeat, with a statistically significant decrease in blood pressure and heart rate, demonstrating that the impact of artwork in a multi-sensorial experience and in an augmented perception environment is a psychosomatic impact. The psycho-physiological and psychological evaluations carried out for the "In the mirror of the Wonder of Luca Giordano" project allowed us to confirm the effectiveness of the design choices of the exhibition in amplifying the perception of art and in improving the relationship between art and the visitor. Moreover, our experience suggests that projects such as "In the mirror of the Wonder of Luca Giordano" could be very useful tools for cultivating aesthetic intelligence and could be developed in museums alongside more common tools and methods.
\end{abstract}

Key words:

Aesthetic experience, Exhibition Design, multi-sensorial experience, heart rate, blood pressure.

SDH Reference:

Andrea Bonacchi et al. 2018. Multidisciplinary Psychosomatic Assessment for UX Design

Evaluation. SDH, 2, 1, 106-120.

DOI : $10.14434 /$ sdh.v2i1.25652

\section{INTRODUCTION}

"In the mirror of the Wonder of Luca Giordano" (https://artperception.org/luca-giordano) took place in 2007 in the Palazzo Medici Riccardi, in Florence. The vault of the gallery, frescoed by Luca Giordano

Author's address: Andrea Bonacchi and Antonella Ferrari, Centro Studi e Ricerca Synthesis, Via Stenterello 10, 50142, Florence, Italy; email:andreabonacchi@centrosynthesis.it; Lelio Camilleri, Centro Tempo Reale, via Pisana 77, 50143, Florence, Italy; email: info@leliocamilleri.it; Francesca Chiesi, University of Florence, Dept. of Neurosciences, Via S. Salvi 12, 50135, Florence, Italy; francesca.chiesi@unifi.it.

(c) [2018] by the author; licensee Studies in Digital Heritage, IU, Bloomington (IN), USA. This article is an open access article distributed under the terms and conditions of the Creative Commons Attribution License (CC BY-NC). 
in the sixteenth century for the Riccardi family (Fig.1), was digitally copied through high-resolution photographic mapping. A reproduction of this was shown in full size on the ground in the same gallery.

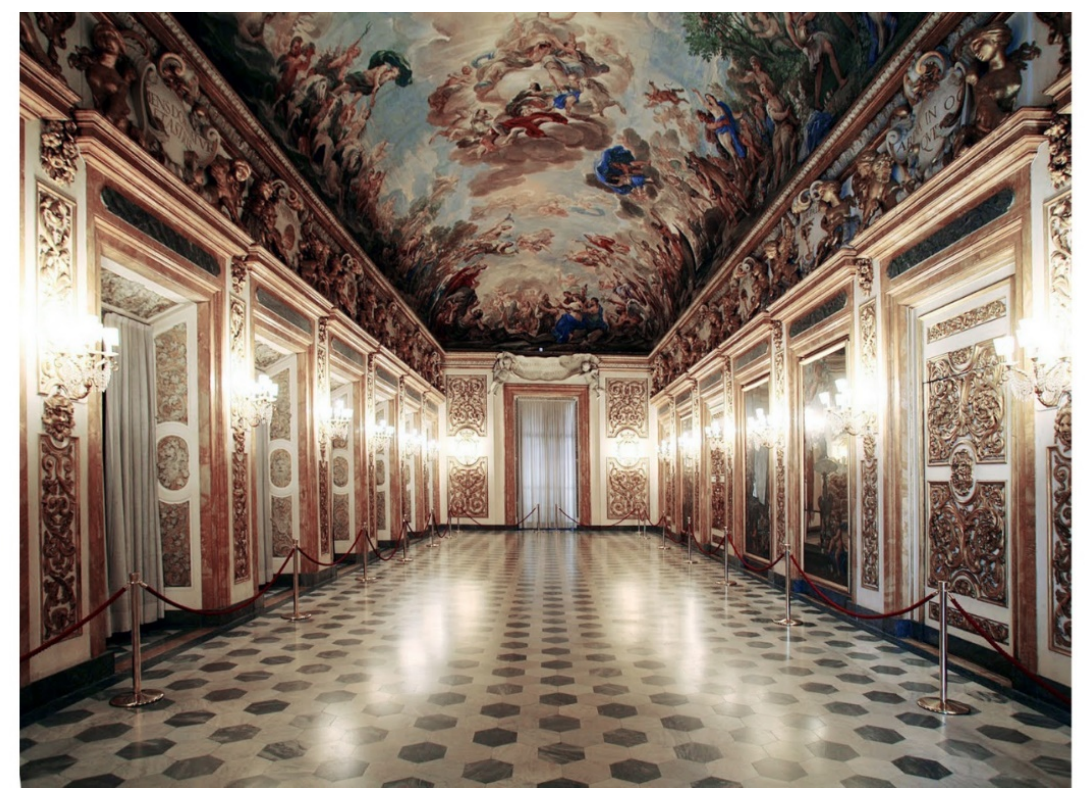

a)

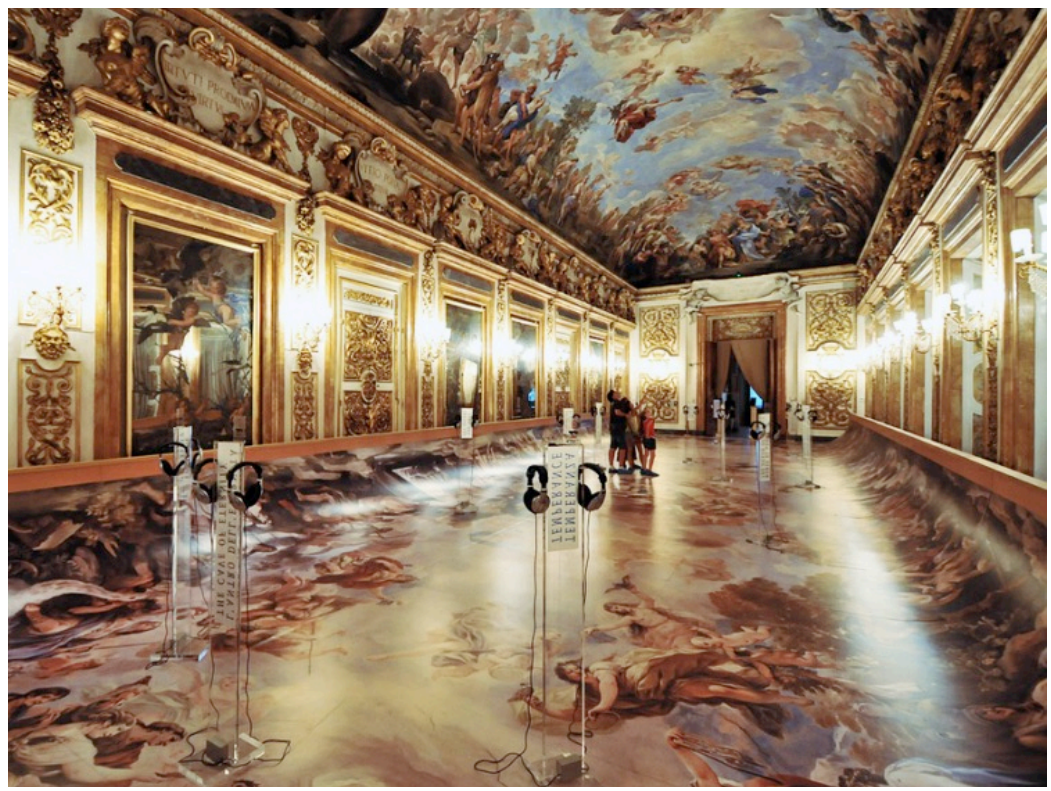

b)

Figure 1. Luca Giordano Gallery (in Palazzo Medici Riccardi, Florence, Italy): a) before and b) during the exhibition. 
Visitors were able to "walk" on the painting reproduced on the floor, experiencing physical contact with the artwork. This was a direct and engaging experience. Visitors were able to see the details of the brush strokes and to enjoy the excellent pictorial quality. Visitors were also able to experience immersion in narrative themes by "coming into contact" with the complex and strikingly impressive iconography of the vault.

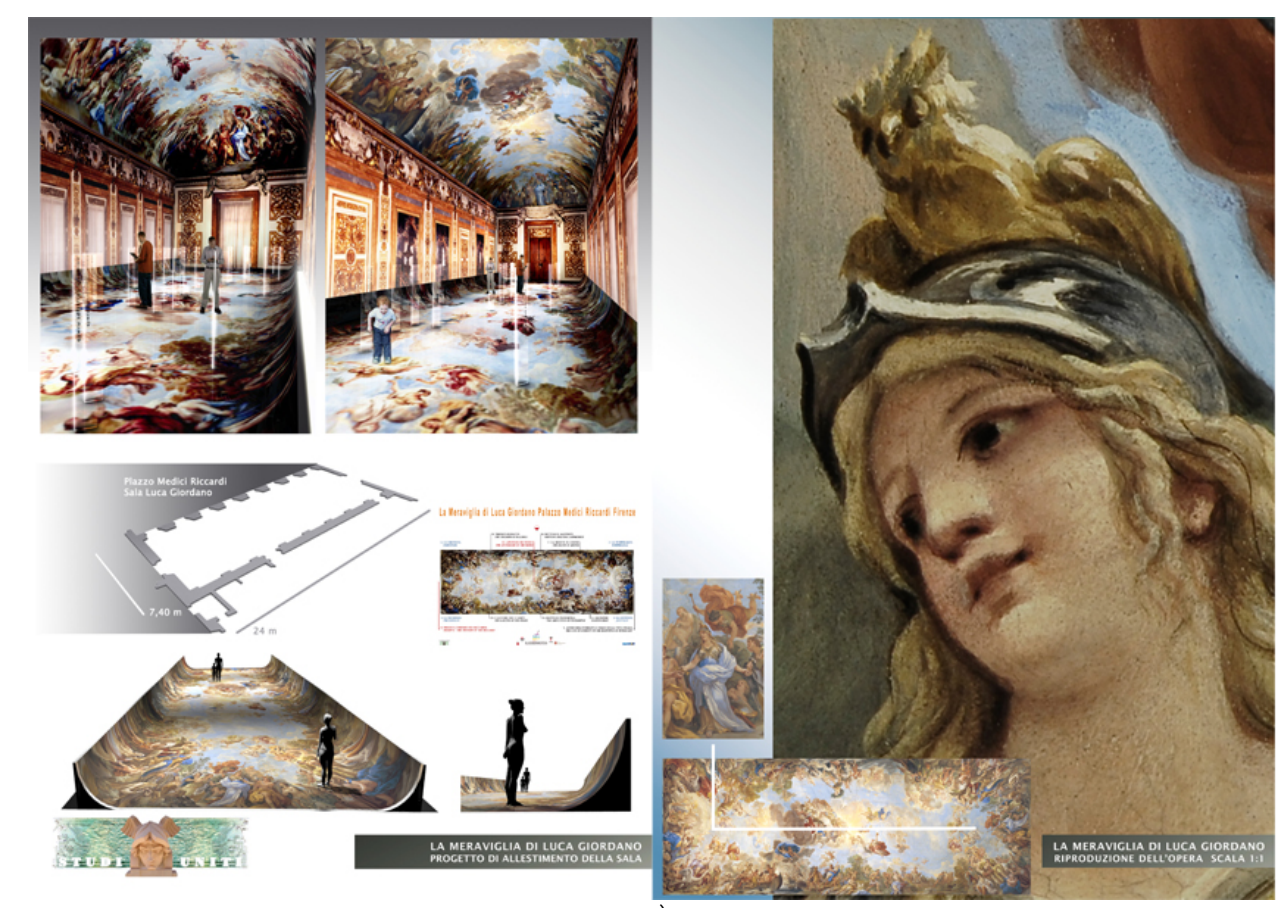

a)

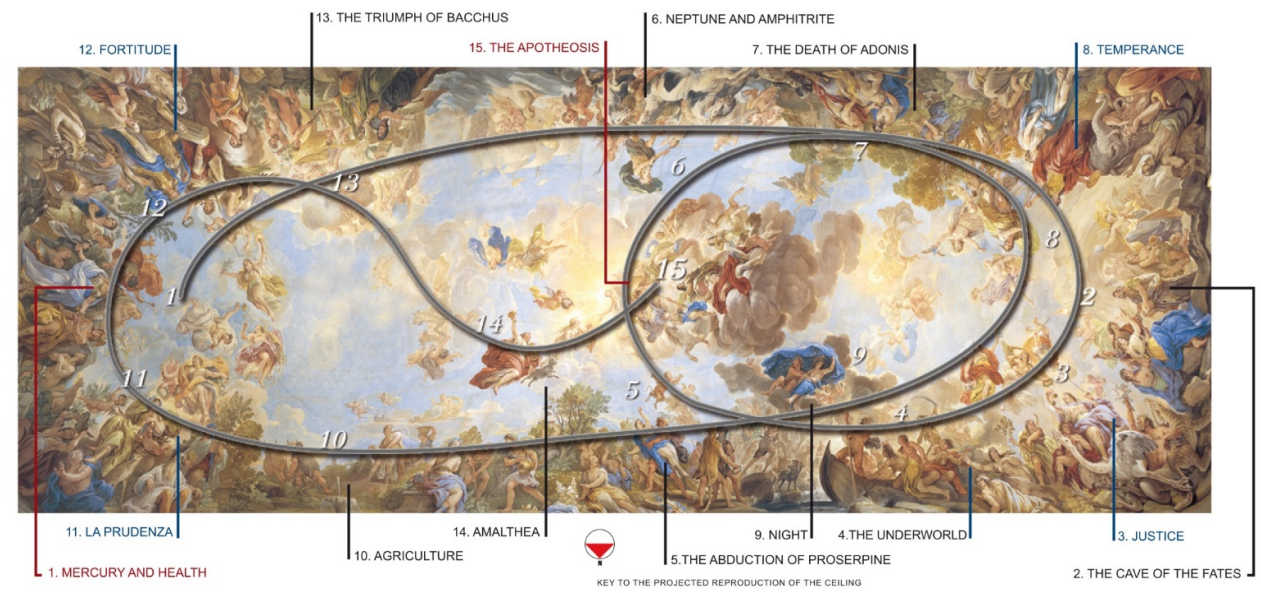

b)

Figure 2. In the mirror of the Wonder of Luca Giordano, Luca Giordano Gallery in Palazzo Medici Riccardi, Florence, Italy: a) the project; b) map of itinerary. 
The author of the exhibition, the scenographer Perla Gianni Falvo, proposed in 2010 to further enrich this experience [Gianni Falvo P., 2015 and 2016]. The aim of this second exhibition was to increase the possibilities for visitors to further engage with the artwork and with themselves, through the artwork. The reproduction of the vault of the gallery frescoed by Luca Giordano was set up again on the floor in the same gallery. On this occasion, a path was also created in which the various allegorical images of the painting became stages of a journey of representation and symbolization of the individual experience of each human being (Fig. 2).

In the fresco by Luca Giordano, we can distinguish at least four different themes: (1) At the four corners, the Cardinal Virtues that guide man on his earthly journey: Justice, Temperance, Prudence and Fortitude. (2) The beginnings of human life and its passage through the various ages towards different destinies; (3) The Triumph of the Riccardi family; and (4) The Apotheosis of the house of Medici through the practice of the cardinal Virtues and their astral glorification [Millen, 1965].

An itinerary was developed in 15 stages, each corresponding to a part of the fresco; each stage was chosen to dramatize the story for visitors reaching this part of the itinerary.

Visual perception was also integrated with sound, leading to further reflections and emotional amplifications; sounds and musical pieces were used for each stage of the itinerary and were integrated with the images and symbols that accompany them. This aspect was taken care of by Anna Meazza and Gino Piovani of the Atelier di Movimento center, which specializes in psychomotor and audio-psycho-phonological education and rehabilitation, assisted by Francesco Giomi [Tomatis, 1992].

In any context in which music is connected to visual media, its action changes the perception and cognition of the images, fixed or in motion. Music or sound adds a value which alters the meaning of the visual object perceived [Chion, 1994]. This effect can be experienced in many audio-visual contexts such as movies, or any kinds of media which combine music/sound and images.

The music was made up of different musical structures, composed of several sequences of classical music of different styles transformed at various levels of surrogacy. In addition, each structure contains water sounds, transformed or in their original shape.

The idea of using sequences of classical music of different styles is to complement the complexity of the Luca Giordano paintings, which depict different kinds of scenes and allegories. The musical structures were prepared to allow the listener to shift from known sounds to more remote ones: the continuous changing soundscape stimulates the listener to be immersed in the complex visual structure and to appreciate the different meanings the same images might have when combined with different sounds or musical sequences.

The water sounds, which represented the presence of the river Arno in the city, are an element of continuity linking each of the sequences. As a result, each distinct sequence contains a recurring sound element. In this way, the listener is continuously faced with known and unknown sounds both in the same sequence and in the following ones.

The complexity of the paintings was therefore complemented by the complexity of the musical structure, while the continuity of the structure of the images were contrasted with the temporal articulation of the sounds interspersed with silences. 
At the end of the exhibition in the gallery, lasting about thirty minutes, the visitors were accompanied to an adjacent room where they had about half an hour to describe the experience in writing and possibly through drawing (writing/ drawing short workshop).

This multisensory experience, as a whole, was very profound and interesting. Therefore, we tried to enter "into the experience" by involving visitors in an impact assessment. The research involved principally psycho-physiological, qualitative psychological and neuro-physiological aspects. Psycho-physiological research is based on the measurement of various normal outputs from the human body (heart rate, respiration, oxygen consumption, etc.), which are an expression of psychoemotional correlates. In particular, we focused on the assessment of blood pressure and heart rate of a sample of visitors during the itinerary of images, symbols and sounds to assess the reaction of the integrated psyche-soma system. In qualitative psychological research, behaviors, ideas, actions and experiences are not measured using statistical analysis as in quantitative research. On the contrary, detailed descriptions are written and explanations of the investigated phenomena are collected. To evaluate neuro-physiological aspects, the technique of the electroencephalogram (EEG) was applied.

After the conception of the exhibition in 2010, a multidisciplinary working group was set up, so that all the various aspects of the project could be integrated from the beginning. For example, the contribution of each specialist was valuable when choosing between the use of diffused or individual music; the specialists then carefully evaluated technical, musical and psychological aspects, in order to offer the visitor the best perceptive amplification of the itinerary. The comparison of opinions of various specialists led to the choice to dedicate a room at the front of the gallery to historical, iconographic and biographical information on the artist and on the methods of research; the information was given through multimedia supports before the exhibition, to allow a purely phenomenological appreciation during the experience. The trans-disciplinary approach has therefore not been interpreted as a juxtaposition of skills, but rather, as an integrated way of working through exchanges and sharing during the entire life-cycle of the project.

\section{THE PSYCHOPHYSIOLOGICAL RESEARCH}

\subsection{Introduction}

Psycho-emotional experiences can trigger changes to certain parameters of body functioning (e.g.: heart rate, blood pressure, breathing rate) through the mediation of the autonomic nervous system.

The enjoyment and appreciation of an artwork has a psycho-emotional impact and is therefore able to modify parameters of body functioning. An extreme and striking example of this impact is Stendhal's syndrome, also called Florence syndrome (since Florence was the town in which it was described the first time), a psychosomatic condition that during the observation of an artwork manifests itself with tachycardia and dizziness, associated with strong emotions and possible disturbances of the sense of perception and of thoughts (as intrusive thoughts) [Magherini 1992; Magherini 2007; Innocenti 2014].

Our research has not focused on pathological aspects, such as Stendhal's syndrome, but rather on physiological aspects of the experience of appreciation of an artwork. Moreover, we have not 
evaluated a habitual appreciation of an artwork, as we were interested in studying the effects of a multisensory experience in an immersive environment; in particular, the aim of the present psychophysiological research was to evaluate the impact of the multisensory exhibition "In the mirror of the Wonder of Luca Giordano" on blood pressure and heart rate.

\subsection{Methods}

The visitors present in the Medici-Riccardi palace, during the seven days in which the psychophysiological and psychological qualitative surveys took place, were invited to participate in the exhibition and an accompanying impact assessment. Inclusion criteria were age (18-80) and the availability of one hour to participate in the experience. Exclusion criteria were the presence of chronic disease, cerebrovascular disease, diabetes mellitus, renal failure, chronic respiratory disease and pregnancy. Characteristics of the 218 volunteers who participated in the study are summarized in Table 1. All participants gave informed consent to participate in the study.

Table 1. Characteristics of the 218 participants to the experiment.

\begin{tabular}{|c|c|c|c|}
\hline \multirow{2}{*}{ Gender } & \multicolumn{2}{|c|}{ Number } & \multirow[t]{2}{*}{$\%$} \\
\hline & & & \\
\hline & Male & 74 & $33.9 \%$ \\
\hline & Female & 144 & $66.1 \%$ \\
\hline \multicolumn{4}{|l|}{ Nationality } \\
\hline & Italian & 150 & $68.8 \%$ \\
\hline & French & 16 & $7.3 \%$ \\
\hline & Spanish & 11 & $5.0 \%$ \\
\hline & Other & 41 & $18.9 \%$ \\
\hline
\end{tabular}

Profession

\begin{tabular}{|l|c|r|}
\hline Student & 23 & $10.6 \%$ \\
\hline Employee & 50 & $22.9 \%$ \\
\hline Worker & 3 & $1.4 \%$ \\
\hline Freelance & 15 & $6.9 \%$ \\
\hline Teacher & 25 & $11.5 \%$ \\
\hline Retiree & 13 & $6.0 \%$ \\
\hline Artist or musician & 4 & $1.8 \%$ \\
\hline Other & 85 & $39.0 \%$ \\
\hline
\end{tabular}

\section{Educational level}

\begin{tabular}{|l|c|r|}
\hline Elementary school & 6 & $2.8 \%$ \\
\hline Secondary school & 14 & $6.4 \%$ \\
\hline High school & 71 & $32.6 \%$ \\
\hline University & 112 & $51.4 \%$ \\
\hline Missing & 15 & $6.8 \%$ \\
\hline
\end{tabular}

Studies in Digital Heritage, Vol. 2, No. 1, Publication date: December 2018 
Blood pressure and heart rate were measured at three different time points: (1) before visiting the exhibition in the gallery, (2) immediately after the multisensory experience, and (3) after the qualitative description of the experience that the participants made in writing and possibly through drawings (Fig.4).
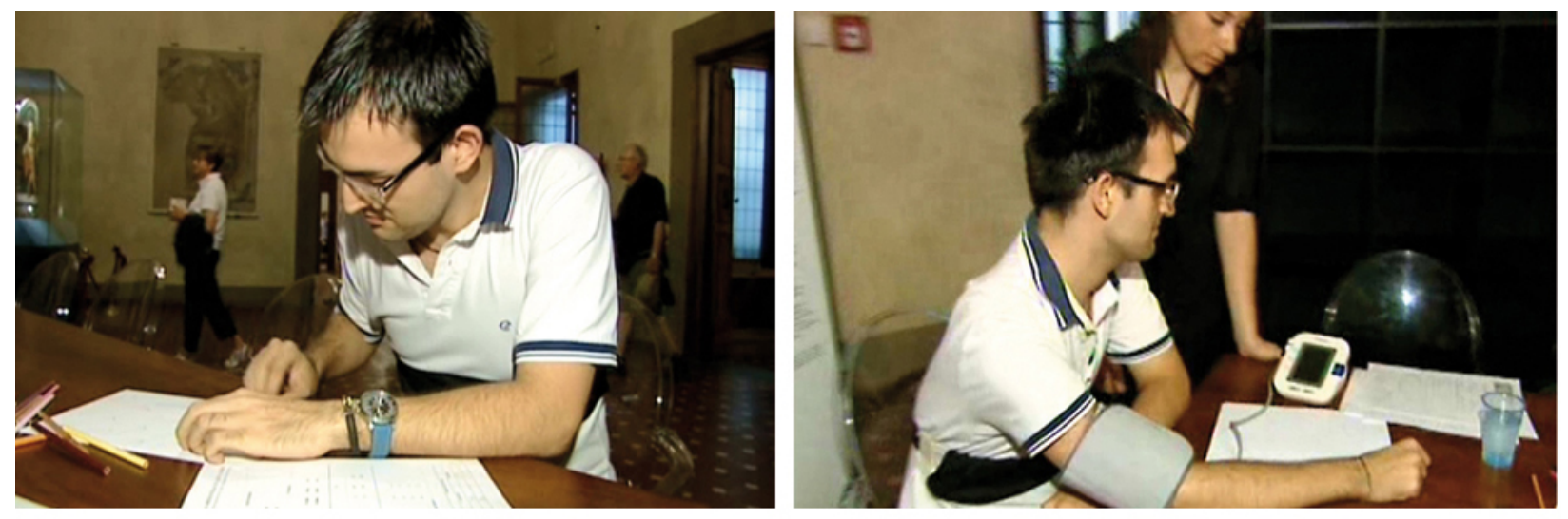

Figure 4. Blood pressure measurement.

\subsection{Statistical Analyses}

A repeated-measures (or within-participants) Analysis of Variance was used to show if a difference exists in diastolic/systolic blood pressure and heart rate of the participants at the different time points (at the beginning, after the multi-sensorial experience, after the drawing/writing lab). To quantify the magnitude of the difference we computed a so called "effect size" index, which can be interpreted as follows: An effect size index of 0.14 or more would be considered a large effect, 0.06 or more a medium effect, and 0.01 or more a small effect. Additionally, we carried out multiple comparisons between every possible combination of pairs of time points. To more thoroughly investigate the effect of the proposed experience, we separately analyzed the differences between time points in low and high diastolic/systolic blood pressure and heart rate participants.

\subsection{Results}

Diastolic blood pressure: Diastolic blood pressure differed significantly but moderately [effect size $=.03$ ] between time points. Specifically, it reduced significantly by an average of 1.32 units from $\mathrm{M}=$ $72.84(\mathrm{SD}=9.70)$ to $\mathrm{M}=71.52(\mathrm{SD}=9.52)$ after the multi-sensorial experience. It then also slightly reduced by an additional $0.37(\mathrm{M}=71.15, \mathrm{SD}=10.64)$ after the drawing/writing lab. This reduction was not, however, statistically significant. On average the difference was 1.69 units (from 72.84 to 71.15) from the beginning to the end of the activities.

Differences between time points in low (lower than or equal to 70) diastolic blood pressure participants $(\mathrm{n}=72$ ) and high (higher than or equal to 80 ) diastolic blood pressure in participants ( $\mathrm{n}$ $=43$ ) showed that the low group did not change between time points (respectively, $\mathrm{M}=63.60, \mathrm{SD}=$ 5.67; $\mathrm{M}=64.72, \mathrm{SD}=8.90 ; \mathrm{M}=62.65, \mathrm{SD}=7.79$ ), whereas a marked change [effect size $=.28$ ] was observed in the high group (respectively, $\mathrm{M}=86.07, \mathrm{SD}=4.52 ; \mathrm{M}=80.28, \mathrm{SD}=7.57 ; \mathrm{M}=82.26, \mathrm{SD}=6.12$ ). 
Specifically, diastolic blood pressure reduced by an average of 5.79 units after the multi-sensorial experience and by an average of 3.81 units from the beginning to the end of the activities (Figure 5).

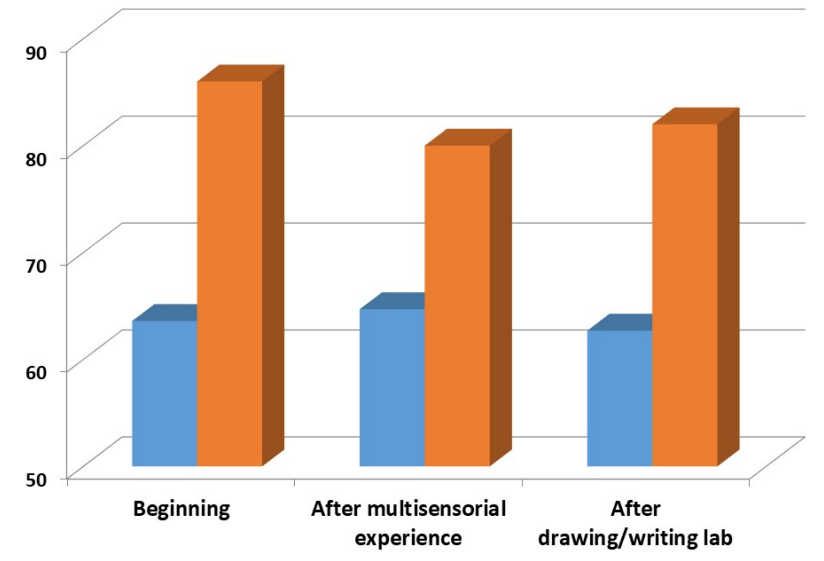

a)

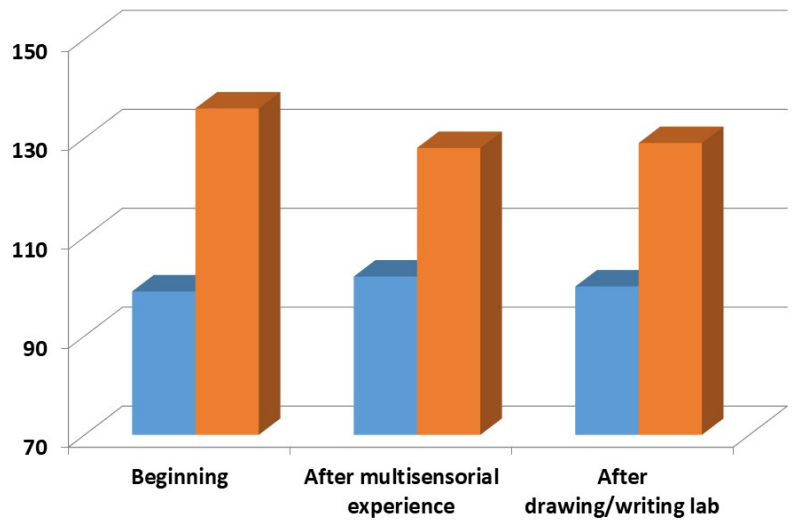

b)

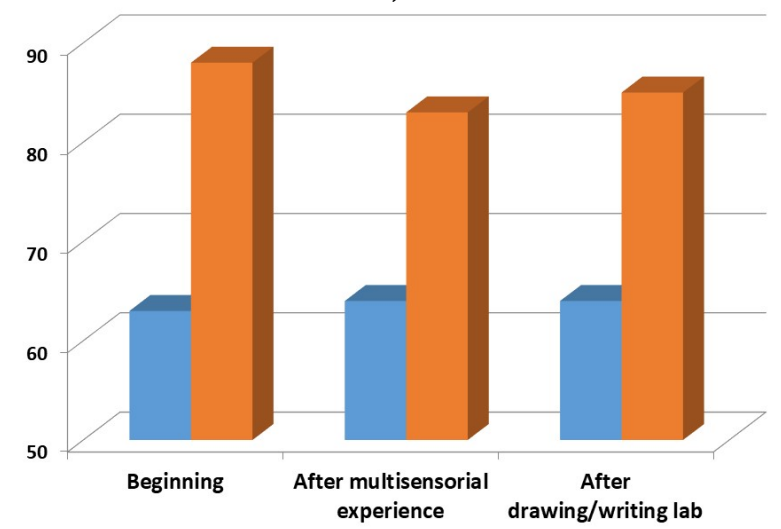

c)

Figure 5. Differences at different moments between: a) diastolic blood pressure; b) systolic blood pressure; c) heart rate. Participants were divided into two subgroups: the subgroup with lower pressure or heart rate values (blue columns) and the subgroup with higher pressure or heart rate values (red columns). 
Systolic blood pressure: Systolic blood pressure differed significantly between time points [effect size $=.03$ ]. It decreased by an average of 2.34 units (from $\mathrm{M}=115.01 ; \mathrm{SD}=16.74$ to $\mathrm{M}=112.67 ; \mathrm{SD}=15.60$ ) after the multi-sensorial experience $(\mathrm{p}<0.05)$. After which it decreased by an additional $0.91(\mathrm{M}=$ $111.75, \mathrm{SD}=18.82$ ) following the writing/ drawing laboratory. Again, the difference was not statistically significant $(p=1.00)$. Overall, systolic blood pressure reduced by an average of 3.25 units (from 115.01 to 111.75) from the beginning to the end of the activities $(p<0.01)$.

Differences between time points in low (lower than or equal to 110) systolic blood pressure participants $(\mathrm{n}=73)$ and high (higher than or equal to 125$)$ systolic blood pressure participants $(\mathrm{n}=$ 51) showed that the low group did not change between time points (respectively, $M=99.15, S D=8.80$; $\mathrm{M}=101.63, \mathrm{SD}=11.72 ; \mathrm{M}=99.74, \mathrm{SD}=11.06$ ), whereas a marked change [effect size = .17] was observed in the high group systolic blood pressure, in which we observed a decrease by an average of 8.00 units (i.e., from $\mathrm{M}=135.67$ to $\mathrm{M}=127.67$ ) after the multi-sensorial experience ( $\mathrm{p}<0.001)$, and by an average of 6.60 units (from $M=135.67$ to $M=129.10)$ from the beginning to the end of the activities $(p<0.01)$.

Heart rate: Heart rate differed significantly between time points [effect size $=.03$ ]. It decreased by an average of 1.97 units (i.e., from $\mathrm{M}=75.07$ with $S D=11.50$ to $\mathrm{M}=73.10$ with $S D=12.06$ ) after the multisensorial experience $(\mathrm{p}<0.01)$, and then it increased by about 1.00 unit $(M=74.08, S D=11.06)$ after the drawing/writing lab, but the difference was not statistically significant $(p=0.34)$. From the beginning to the end of the activities, heart rate decreased by an average of 1.00 unit (from $\mathrm{M}=75.07$ to $\mathrm{M}=$ 74.08). These differences however, failed to reach statistical significance $(p=0.13)$.

Analyzing separately the differences between time points in low (lower than or equal to 70) heart rate participants ( $n=61$ ) and high (higher than or equal to 80) heart rate participants ( $n=53$ ), we observed that heart rate did not change $(\mathrm{p}=0.44)$ between time points (respectively, $\mathrm{M}=63.33, \mathrm{SD}=5.64 ; \mathrm{M}=$ 63.89, $\mathrm{SD}=7.30 ; \mathrm{M}=64.18, \mathrm{SD}=9.69$ ), whereas a marked change was observed in the high heart rate group [effect size $=.11$ ]. In particular, post hoc tests revealed that heart rate reduced by an average of 5.19 units (i.e., from $M=88.40 ; S D=7.66$ to $M=83.21 ; S D=13.34$ ), after the multi-sensorial experience $(\mathrm{p}<0.05)$ and by an average of 3.64 units (from $\mathrm{M}=88.40$ to $\mathrm{M}=84.75)$ from the beginning to the end of the activities $(p<0.01)$.

\subsection{Discussion}

It is very interesting to note that the multi-sensorial experience created in the gallery frescoed by Luca Giordano determined a decrease in blood pressure and heart rate that tended to remain even after the short writing / drawing workshop. These changes were more pronounced in the participants who had higher basal blood pressure and frequency levels. Therefore, the multi-sensorial experience appeared to induce an overall effect on the cardiovascular system compatible with a relaxation response mediated by a decreased sympathetic nerve activity [Benson 2000].

The effects detected are similar in magnitude to those observed with other methods capable of inducing a relaxation response, such as music-guided slow breathing [Grossman 2001; Modesti 2010].

Further studies are needed to better understand these effects of a multi-sensorial enjoyment of an artwork and the related psychophysiological mechanisms. 


\section{THE QUALITATIVE PSYCHOLOGICAL RESEARCH}

The multi-sensory exhibition "In the mirror of the Wonder of Luca Giordano" was associated with a subsequent creative writing or drawing workshop in which the visitors who had participated in the psycho-physiological research were also invited to describe their personal experience and feelings. In particular, we used "creative writing," a type of writing that enhances the narrative, emotional and creative content, to the detriment of the lexical and syntactic form. Thanks to the presence of an art therapist, some of the participants decided to represent their psycho-emotional state also with a drawing (e.g. in Fig. 6).

b)

a)
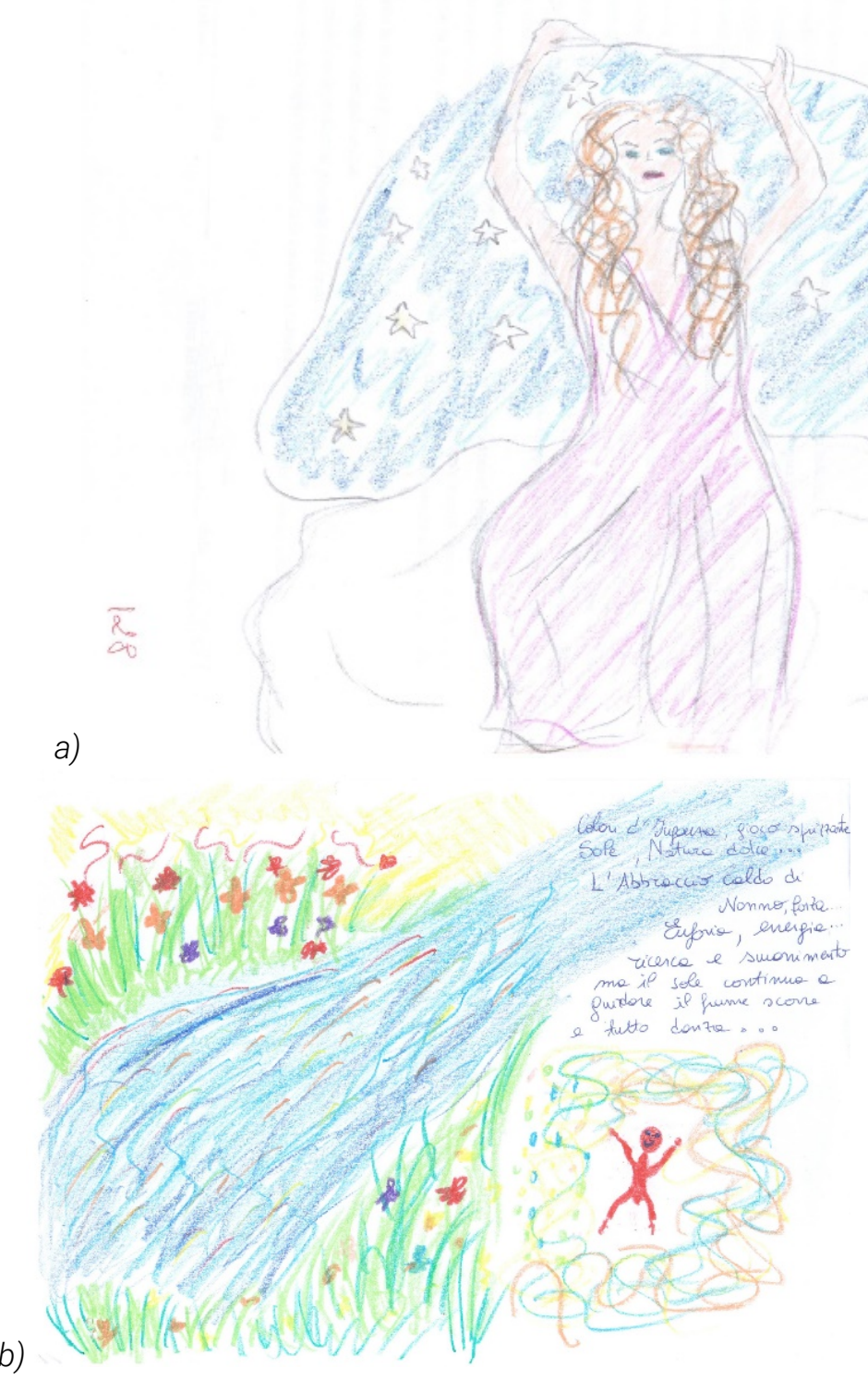

c)

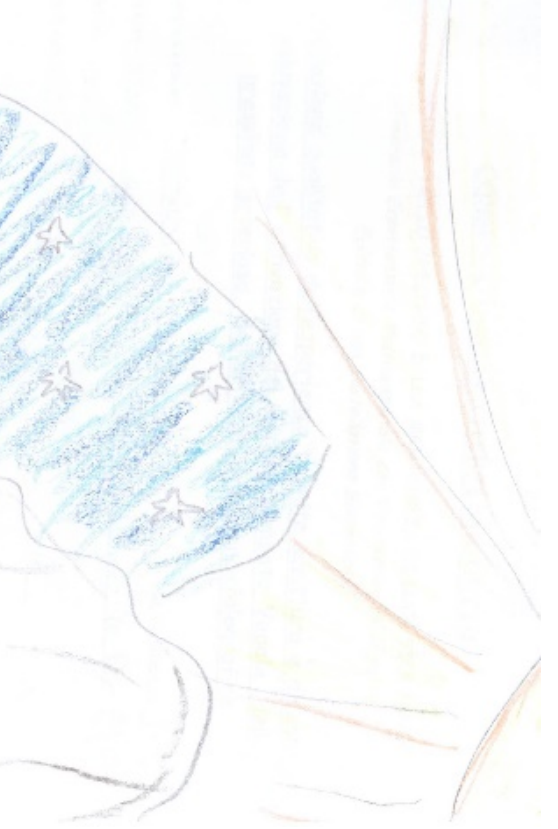

Figure 6: Examples of drawings representing psycho-emotional state immediately after the multisensory experience 


\section{2:116 A. Bonacchi, et al.}

We decided to analyze this interesting collection of information using a qualitative method. Qualitative methods of research in the psychological field are those that collect data in the form of interviews, words, observations, visual images and documents. Qualitative techniques are characterized by less structuring and greater flexibility than quantitative techniques and are particularly useful when investigating new and dynamic situations. In particular, the thematic analysis [Braun, 2006] was used as a method of analyzing written texts. The texts were examined and coded independently by two researchers. The respective coding was subsequently compared and discussed among the researchers until they reached an agreement.

The main themes that emerged were:

(1) Enjoyment of the experience (e.g. "I have experienced freshness and pleasure as well as joy"; "I find beautiful the idea and the emotions that you made me experience")

(2) Fun (e.g. "the experience was fun and interesting")

(3) Relaxation (e.g. "thanks for this engaging and relaxing experience")

(4) Emotional intensity ("e.g. "I experienced many passages of emotions: love, pride, vitality, passions, pain, harmony" ... ; It was new and above all exciting")

(5) Involvement and immersion (e.g. "I felt like I was one of figures in the fresco"; "it seems to enter a fantastic world")

(6) Reproduction of the fresco on the floor as an enriching and facilitating experience of the artwork (e.g. "walking on the reproduction of the fresco gave me the opportunity to better appreciate the fresco;"; "walking on the fresco allows you to enter with greater intensity into what you are watching").

(7) Pleasure of the integration of music in the experience (e.g. "the addition of music to the visit has increased my concentration")

(8) Lightness (e.g. "It was relaxing, I went out and felt light ")

(9) Sense of space-time suspension (e.g. "all scenes become a single infinite, timeless moment").

(10) Accurate and detailed remembrance of what was seen and experienced (e.g. "With the music I see the pictures so slowly, I know now I can remember them better"; "standing at the various stations with the music made me pay greater attention to the observed scenes").

Less than $5 \%$ of participants reported a sense of restlessness, perplexity, anxiety, fatigue or boredom.

Disruption or distraction due to the presence of music was reported by about a quarter of the participants. This may be because in some stations of the path the frequency of the music had been progressively altered to evoke characteristics similar to prenatal listening. Visitors participating in the study received an introduction that included panels, videos, multi-language brochures, maps, and descriptions of the itinerary that were aimed at elucidating both the historical and aesthetic aspects of the work and the goals and methods of the project. This introduction included information concerning sound. Nevertheless, some visitors mistakenly considered the alteration of the frequencies as a malfunction of the audio system. 
Overall, the experience evoked a sense of pleasure, enjoyment, relaxation, and lightness in most of the visitors who participated in the study. Interesting experiences of space-time suspension could be explained as consequences of an absorption in the artwork and in the dimension of visitors' own inner psycho-emotional resonances. Also, note the fact that some participants were amazed to have acquired memories of the experience and of the artwork which were deeper and more accurate than expected. Scientific studies have demonstrated that on leaving a museum the majority of visitors recall little or nothing of what they have seen - unless they had planned to see a specific artwork.

Having a predetermined time and a visit path probably increased the intensity of the experience and allowed visitors to dwell on specific parts of the fresco to which the attention was directed.

Heterogeneity of personal experiences and of feelings observed through the writing/drawing workshop point toward a varying makeup of the sample visitors experiencing the exhibition with different attitudes, qualities, skills and limits. The differing personal resonances were an expression of the variety of different and subjective psychological processes.

\section{NEUROPHYSIOLOGICAL ASPECTS}

Mental activity involved in our cognitive and "social" processes is generated at the level of the cortical neurons. Cognitive neuroscience uses different instrumental methods (e.g.: Functional Magnetic Resonance Imaging, Electroencephalography, Event-Related Evoked Potentials), which have recently made it possible to highlight the cerebral areas involved in specific cognitive processes. After decades in which neuroscience developed in the laboratories, it is now increasingly often being used in "social" contexts. For example, these methods have been applied to the study of the decisional processes employed in the choice of a product to be purchased (Neuromarketing), in choices of an economic type (Neuroeconomics) and even in the assessment of voting decisions (Neuropolitics); more recently other fields of application have included the assessment of the effects of meditative practices on the brain [Kabat-Zinn 2001].

The activity of our neurons takes place through the generation of electrical signals that can be recorded directly on the scalp via special sensors. This electrical activity can be recorded using the technique of the electroencephalogram (EEG), which has been further elaborated using digital technology. The distribution of this electrical activity on the scalp indicates the activation of different areas of the brain.

In our experimental protocol applied in the evaluation of the multi-sensorial experience "In the mirror of the Wonder of Luca Giordano," an EEG was used to establish the cerebral activity of 10 volunteers before visiting the exhibition in the gallery and immediately after the multisensory experience (Fig. 7).

Given the small number of volunteers studied and the technical difficulties encountered, it is challenging to draw conclusions from this study that we can consider preliminary. However, it was very useful to establish the feasibility of an EEG measurement in a multi-sensorial and immersive experience of an artwork. This experience was advantageously used in the subsequent workshop, entitled "Procession in time through to the splendor of the interior epiphany," with an impact assessment that took place in 2014 in the Chapel of Palazzo Medici-Riccardi, frescoed with the 
Procession of the Magi by Benozzo Gozzoli [Gianni Falvo, 2015]. In this workshop, we adopted more advanced systems of scientific-cognitive analysis, supported by technological innovations that make it possible to detect biological parameters and brain mapping in real time; the EEG recordings yielded neurometric indices linked to the variation in the memorization, interest and emotional involvement of the subjects.

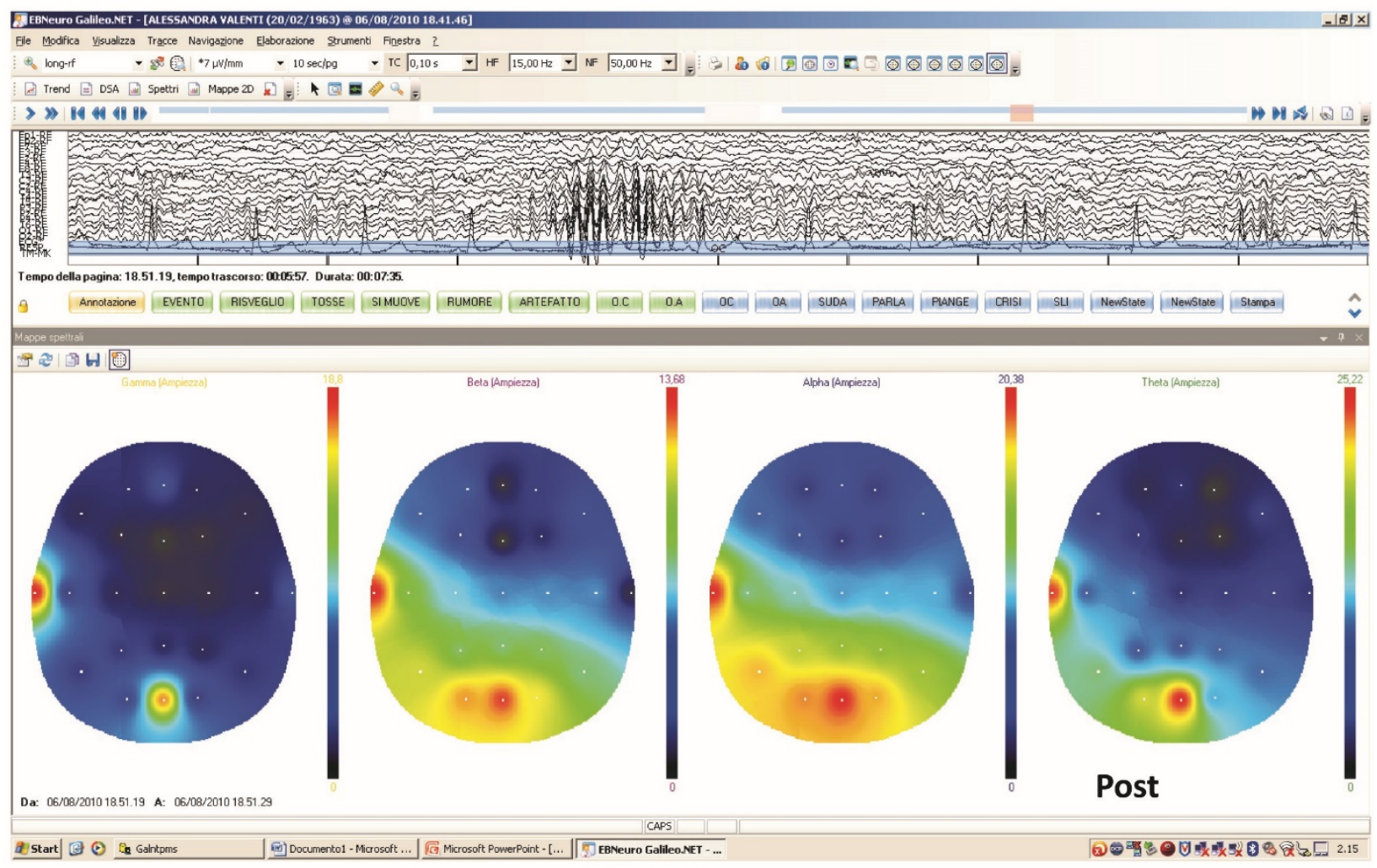

Figure 7: Electroencephalographic mapping.

\section{CONCLUSIONS}

"In the mirror of the Wonder of Luca Giordano" was a pilot project that involved different disciplines and researchers. The experience evoked a sense of pleasure, enjoyment, relaxation, lightness, spacetime suspension, involvement and immersion in most of the visitors who participated in the study. In many of the visitors, the devices detected changes in heartbeat and blood pressure, demonstrating that the impact of artwork in a multi-sensorial experience and in an augmented perception environment is a psychosomatic impact.

In his book, Beauty and the Soul: The Extraordinary Power of Everyday Beauty to Heal Your Life, the Italian psychotherapist and philosopher Piero Ferrucci introduces the concept of "aesthetic intelligence" described as the faculty to perceive beauty and to use it for one's own well-being. This kind of intelligence should be added to the other typologies scientists are talking about: emotional 
intelligence [Goleman, 2004], mathematical and linguistic intelligence, visual intelligence [Gardner, 2006], corporeal intelligence, social intelligence, verbal intelligence etc. Piero Ferrucci states that the fundamental aspects of aesthetic intelligence are: (1) the breadth of the aesthetic range (the ability to perceive beauty in multiple situations); (2) the depth of aesthetic experience (for someone, beauty is a superficial and temporary experience, for others it is a profound and transformative experience); and (3) the ability to integrate beauty (the ability to be positively transformed by contact with the artwork).

In contrast to the more and more frequent manifestation of Museum Fatigue Syndrome [Gilman, 1916], years later some of the volunteers who took part in the study still remember the experience with pleasure and often in great detail. For some of them, it has determined a change in their relationship with works of art. For example, some have referred to the desire to take advantage of multisensory experiences in normal museum tours. Others have emphasized that this experience has helped them to value not the quantity of artworks seen in a museum but to the particular relationship and resonance established with a selection of them. To the researchers involved in the project, this experience has suggested that a multidisciplinary approach to the realization of a museum itinerary can be fundamental in improving its enjoyment and in amplifying the aesthetic experience.

The psycho-physiological and psychological evaluations carried out for the "In the mirror of the Wonder of Luca Giordano" project allowed us to confirm the effectiveness of the design choices of the exhibition in amplifying the perception of the work of art and in improving the relationship between the work of art and the visitor. Moreover, our experience suggests that projects such as "In the mirror of the Wonder of Luca Giordano" could be a very useful tool for cultivating aesthetic intelligence and could be developed in museums alongside the more classical paths of enjoyment and appreciation.

\section{ACKNOWLEDGEMENTS}

The authors want to thank the members of the multidisciplinary working group that was specially set up for this research, particularly the scenographer and researcher Perla Gianni Falvo (concept and general coordination); Pietro Amedeo Modesti, specialist in Internal Medicine, cardiologist, Critical Medical Surgery Department, Faculty of Medicine of the University of Florence; Antonello Grippo, neurologist, and Giovanni Lanzo, University Hospital of Careggi (Florence); Giovanni Pioggia, bioengineer, Gennaro Tartarisco, Giovanni Baldus, Daniele Corda, Institute of Clinical Physiology of the CNR of Pisa: Anna Meazza and Gino Piovani, "Atelier di Movimento" (center specialized in motor, psychomotor and audio-psycho-phonological education and re-education); Francesco Giomi, Damiano Meacci Fondazione Tempo Reale,; Lapo Felicioni, Monica Guazzini, Stefania Romano and Alessandro Toccafondi psychotherapists and art therapists of the Psychosynthesis Center of Firenze. 
2:120 A. Bonacchi, et al.

\section{REFERENCES}

Benson Herbert. 2000. The Relaxation Response Avon A, Expanded, Updated ed.

Braun V, Clarke V. 2006. Using thematic analysis in psychology. Qualitative research in psychology, 3, 77-10.

Chion, M. 1994. Audio-vision. Sound on Screen. New York, Columbia University Press

Ferrucci P. 2010. Beauty and the Soul: The Extraordinary Power of Everyday Beauty to Heal Your Life Tarcherperigree; Reprint ed.

Gardner Horward. 2006. Multiple Intelligences: New Horizons in Theory and Practice, Basic Books, Reprint ed.

Gianni Falvo P. et al. 2014. Workshop with impact assessment in the chapel of the Magi in Palazzo Medici Riccardi, Florence Augmented reality with multimedia and cognitive technologies IEEE Xplore Conference. DOI: 10.1109/VSMM.2014.7136677.

Gianni Falvo P. 2015 Exhibit design with multimedia and cognitive technologies, impact assessment on Luca Giordano, Raphael, the Chapel of the Magi in Palazzo Medici Riccardi, Florence, DigitalHeritage International Congress, Granada (Spain).

Gianni Falvo P. and D'Annibale E. 2016. A Virtual itinerary for a real experience. The Frescoes of the Chapel of the Magi in Palazzo Medici Riccardi, Florence SCIRES - SCIentific RESearch and Information Technology, 6(1), 41-50, e-ISSN 2239-4303

Gilman Benjamin Ives, 1916. Museum Fatigue syndrome: A term that characterises decreased visitor interest towards exhibits as visits progress. (1852-1933) The Scientific Monthly 2 (1), 62-74.

Goleman D. 2004. Emotional intelligence. Random USA.

Grossman E, et al. 2001. Breathing-control lowers blood pressure. J Hum Hypertens. 15(4), 263-269.

Innocenti C. et al. 2014. The Stendhal Syndrome between psychoanalysis and neuroscience, Riv Psichiatr., 49(2), 61-66.

Kabat-Zinn J. 2001. Mindfulness Meditation for Everyday Life. Piatkus.

Magherini G. 1992. La sindrome di Stendhal, Feltrinelli ed.

Magherini G. 2007. Mi sono innamorato di una statua. NICOMP L.E. ed. Firenze.

Millen R. 1965. Luca Giordano a Palazzo Medici Riccardi Sadea Sansoni Ed.

Modesti P.A. et al. 2010. Psychological predictors of the antihypertensive effects of music-guided slow breathing. J Hypertens, 28(5), 1097-1103. doi: 10.1097/HJH.0b013e3283362762.

Tomatis Alfred and Walter Passerini. 1992. Management dell'Ascolto. Franco Angeli Editore.

Received September 2018; revised October 2018; accepted December 2018.

Studies in Digital Heritage, Vol. 2, No. 1, Publication date: December 2018 